\title{
Biomechanical conditioning of the motor unit transitory force decrease following a reduction in stimulation rate
}

\author{
Joanna Rakoczy ${ }^{{ }^{*} \text { (D) }}$, Katarzyna Kryściak ${ }^{1}$, Hanna Drzymała-Celichowska ${ }^{1}$, Rositsa Raikova ${ }^{2}$ and Jan Celichowski ${ }^{1}$
}

\begin{abstract}
Background: The biomechanical background of the transitory force decrease following a sudden reduction in the stimulation frequency under selected experimental conditions was studied on fast resistant motor units (MUs) of rat medial gastrocnemius in order to better understand the mechanisms of changes in force transmission.

Methods: Firstly, MUs were stimulated with three-phase trains of stimuli (low-high-low frequency pattern) to identify patterns when the strongest force decrease (3-36.5\%) following the middle high frequency stimulation was observed. Then, in the second part of experiments, the MUs which presented the largest force decrease in the last low-frequency phase were alternatively tested under one of five conditions to analyse the influence of biomechanical factors of the force decrease: (1) determine the influence of muscle stretch on amplitude of the force decrease, (2) determine the numbers of interpulse intervals necessary to evoke the studied phenomenon, (3) study the influence of coactivation of other MUs on the studied force decrease, (4) test the presence of the transitory force decrease at progressive changes in stimulation frequency, (5) and perform mathematical analysis of changes in twitch-shape responses to individual stimuli within a tetanus phase with the studied force decrease.

Results: Results indicated that (1) the force decrease was highest when the muscle passive stretch was optimal for the $\mathrm{MU}$ twitch $(100 \mathrm{mN})$; (2) the middle high-frequency burst of stimuli composed of at least several pulses was able to evoke the force decrease; (3) the force decrease was eliminated by a coactivation of $10 \%$ or more MUs in the examined muscle; (4) the transitory force decrease occured also at the progressive decrease in stimulation frequency; and (5) a mathematical decomposition of contractions with the transitory force decrease into twitchshape responses to individual stimuli revealed that the force decrease in question results from the decrease of twitch forces and a shortening in contraction time whereas further force restitution is related to the prolongation of relaxation.
\end{abstract}

Conclusions: High sensitivity to biomechanical conditioning indicates that the transitory force decrease is dependent on disturbances in the force transmission predominantly by collagen surrounding active muscle fibres.

Keywords: Motor unit, Unfused tetanus, Rate coding, Force regulation, Stimulation frequency

\footnotetext{
* Correspondence: joanna.rakoczy89@gmail.com

'Department of Neurobiology, Poznan University of Physical Education, 27/

39 Królowej Jadwigi Street, 61-871 Poznań, Poland

Full list of author information is available at the end of the article
}

\section{$\triangle B M C$}

(c) The Author(s). 2020 Open Access This article is licensed under a Creative Commons Attribution 4.0 International License, which permits use, sharing, adaptation, distribution and reproduction in any medium or format, as long as you give appropriate credit to the original author(s) and the source, provide a link to the Creative Commons licence, and indicate if changes were made. The images or other third party material in this article are included in the article's Creative Commons licence, unless indicated otherwise in a credit line to the material. If material is not included in the article's Creative Commons licence and your intended use is not permitted by statutory regulation or exceeds the permitted use, you will need to obtain permission directly from the copyright holder. To view a copy of this licence, visit http://creativecommons.org/licenses/by/4.0/. The Creative Commons Public Domain Dedication waiver (http://creativecommons.org/publicdomain/zero/1.0/) applies to the data made available in this article, unless otherwise stated in a credit line to the data. 


\section{Background}

The modulation of motor unit (MU) force during voluntary activity is attained by changes in the rate of motoneuronal firing $[3,21]$. The unfused tetanic contractions are sums of twitch-shape responses to successive motoneuronal firings. The amplitude and time parameters of these responses are considerably variable [8]. Numerous studies concerning the sensitivity of MUs to the stimulation pattern indicated that force production is a nonlinear process. On the one hand shortening of a single interpulse interval evokes the catch effect $[5,10,15]$, on the other hand its prolongation evokes the tetanic depression [7, 9]. Recently, a new physiological phenomenon of a transitory force decrease after a sudden reduction in the stimulation frequency was found [16]. The contractions of isolated MUs were evoked by three-phase trains of stimuli with a low-high-low frequency pattern, and the amplitude of the transitory force decrease during the last phase exceeded even $30 \%$ of the force level, which was reached at the end of the second low frequency stimulation. The mechanisms of this effect have not been explained as yet. A previous study suggested that the transitory force decrease probably has a biomechanical background, involving processes of the force transmission by collagen within the muscle, because the phenomenon was found for only one-half of studied MUs, most frequently fast-resistant (FR) ones [16]. These units in the studied medial gastrocnemius muscle were found to be distributed predominantly within the proximal compartment [27], corresponding to only $40 \%$ of the muscle length [26], which indicates that their force is transmitted by collagen structures in the distal compartment.

Therefore, in the present study, we investigated the importance of biomechanical factors for the transitory force decrease, analysing effects of muscle passive stretching and parallel tetanic contractions of other MUs in the same muscle. These two factors are expected to influence force transmission by intramuscular collagen. In addition, we tested whether a shortening of only one interpulse interval within the train at a stable frequency (the shortest possible middle high-frequency phase) is able to evoke the studied force decrease after a force increase and how a progressively increasing number of pulses at a high rate influence the described effect. Then, the presence of a transitory force decrease at progressive changes in the stimulation frequency was tested in the contractions evoked by trains of stimuli with sinusoidal changes in frequency because a sudden switch from higher to lower frequency in the motoneuronal firing rate is not observed during voluntary activity whereas trains of stimuli with sinusoidal changes in frequency are similar to the normal behaviour of motoneurons. Finally, to more deeply understand the studied phenomenon, a mathematical decomposition of tetanic contraction with the studied transitory force decrease into a train of twitch-shape responses to successive stimuli was performed. The decomposition method is based on modeling of individual twitch forces attributed to each stimulus by progressive subtraction of successive twitch-shape curves from the unfused tetanus curve in order to follow the changes of the twitch properties leading to the studied force decrease [23].

Better understanding of the studied phenomenon could improve actual knowledge of the role of rate coding in motor control. Especially, we hypothesized that the phenomenon influence the force at progressively decreasing stimulation frequency and a confirmation of this hypothesis is important to better understand mechanisms shaping muscle force when motoneurons are decreasing firing rate, a process observed usually in human experiments when force of contraction is decreasing before the end of muscle activity.

\section{Methods \\ Ethical Aprroval}

All procedures were made to minimize the suffering of the examined animals and were approved by the Local Ethics Committee for Experiments on Animals (number of Permission: 2/2015). Additionally, various principles of laboratory animal care (Guiding Principles for the Care and Use of Animals in the Field of Physiological Sciences, the Polish Law on the Protection of Animals, and European Union regulations) were followed. Experiments were performed on Wistar rats, which were bought from Wielkopolska Center for Advanced Technologies in Poznan, owner of an animal house designed to perform experiments in conditions of GLP (Good Laboratory Practice).

\section{Surgery and experimental procedures}

Experiments were performed on 10 female Wistar rats (4-5 months) weighing $256.4 \pm 35.1 \mathrm{~g}$. Before the experiments, the rats were kept in cages equipped with running wheels to ensure a moderate level of their activity, in an animal room with a 12:12 light/dark cycle and controlled temperature $\left(22 \pm 2^{\circ} \mathrm{C}\right)$ and humidity $(55 \pm 10 \%)$. All rats had unrestricted access to standard laboratory food and tap water throughout the study period.

During experiments, the animals were anesthetized (sodium pentobarbital; initial dose of $60 \mathrm{mg} / \mathrm{kg}$, i.p. supplemented approximately with doses of $10 \mathrm{mg} / \mathrm{kg} / \mathrm{h}$ ). The depth of anaesthesia was controlled by the observation of pinna and withdrawal reflexes. After the experiments the animals were euthanized (sodium pentobarbital, $180 \mathrm{mg} / \mathrm{kg}$ ).

The studied muscle and sciatic nerve were separated from surrounding tissues, while other hind limb muscles 
were denervated. Laminectomy was performed over the L2-L6 vertebrae. The ventral roots were cut close to the spinal cord. The animals were immobilized with steel clamps placed on the tibia, the sacral bone, and the L1 vertebra. The hind limb under study was immersed in a chamber filled with paraffin oil (temperature-regulated automatically at $37 \pm 1{ }^{\circ} \mathrm{C}$ ) and the spinal cord was similarly covered with the oil. The muscle was connected through the Achilles tendon to a force transducer (deflection of $100 \mu \mathrm{m}$ per $100 \mathrm{mN}$ ), which measured both the isometric force and the muscle passive tension.

The functional isolation of single MUs was achieved by splitting the L 5 or L4 ventral roots into thin filaments electrically stimulated with rectangular pulses (amplitude up to $0.5 \mathrm{~V}$, duration of $0.1 \mathrm{~ms}$ ). The MU action potentials were recorded with bipolar silver wire electrodes inserted into the muscle. The 'all-or-none' appearance of twitch and MU potentials at increasing amplitudes of stimuli indicated the activity of single MU. All data were recorded on a computer disc using a 12-bit analogue-todigital converter (sampling rates of $1 \mathrm{kHz}$ and $10 \mathrm{kHz}$ for force and action potentials, respectively).

In this study, $122 \mathrm{MUs}$ of rat medial gastrocnemius were investigated. Seventy of them (51 FR, 10 FF, and 9 $\mathrm{S}$ MUs) revealed the transitory force decrease of at least a 3\% amplitude and were included into the experimental procedures described below. MUs were classified into fast (F) and slow (S) based on the presence of sag in 40 $\mathrm{Hz}$ contraction [4]. However, due to artefacts in the force recordings, weak studied effect, low force, and high noise-to-signal ratio (mainly in the S MUs) as well as considerable instability in force due to the fatigue (mainly in the FF MUs), only 46 FR units were analysed.

\section{The experimental protocol}

All MUs tested during our experiments were initially stimulated according to following steps:

I. MUs classification and transitory force decrease appearance:

1. Five pulses at $1 \mathrm{~Hz}$ (twitch forces and action potentials were recorded and averaged)

2. A $500-\mathrm{ms}$ train of pulses at $40 \mathrm{~Hz}$ (the 'sag' in the unfused tetanus was controlled)

3. A 300 -ms train of pulses at $150 \mathrm{~Hz}$ (the maximum force was determined)

4. For FR MUs, a set of recordings of tetanic contractions evoked with a three-phase train of pulses at changing frequencies in a low-highlow frequency pattern as follows: a 500-ms train of stimuli at low frequency, a 300-ms train at high frequency, and a 500-ms train at the same low frequency as the initial train, respectively. The low frequencies were 15, 20, 25, 30, 35, and
$40 \mathrm{~Hz}$, while the high frequencies were 75,90 and $150 \mathrm{~Hz}$, and all possible combinations of low and high frequencies were tested, i.e., the protocol included 18 trials delivered according to increasing stimulation frequency.

Ten-second intervals between each part of the stimulation protocol were applied.

II. Biomechanical conditioning of the transitory force decrease:

The transitory force decrease in the third phase of the contraction was measured in relation to the force at the end of tetanus. When its amplitude exceeded $3 \%$ and the MUs were stable in force, these MUs were selected for the following additional steps of the experiment. For each of them, one of the protocols described below was applied (based on the pattern from step 4., which has evoked the strongest transitory force decrease):

1. Recordings of one to five tetanic contractions (low frequencies ranging from 25 to $35 \mathrm{~Hz}$, combined with high 75 and/or $90 \mathrm{~Hz} ; 35$ stimulations) were repeated at the stable muscle passive stretches of 30 $\mathrm{mN}$, then $100 \mathrm{mN}$, and finally $200 \mathrm{mN}$, set at least $30 \mathrm{~s}$ before recordings and kept constant thoughout a series of recordings (6 MUs) (Fig. 1).

2. A set of tetanic contractions with 1, 2, 4, 6 and 18 short interpulse intervals $(11.1 \mathrm{~ms})$ within the highfrequency phase of stimulation (i.e. in the middle part of trains of stimuli) was recorded. The number of stimuli within the low-frequency phases (35 or $40 \mathrm{~Hz}$ ) was constant (8 MUs) (Fig. 2).

3. The selected recording was repeated during a parallel maximum tetanic contraction of a single MU or group of MUs and separately as a control before and after; additionally, this accompanying tetanic contraction was also recorded separately. The maximum tetanic contraction was evoked by $150 \mathrm{~Hz}$ stimulation delivered for $2000 \mathrm{~ms}$ (channel 1 of the stimulator), whereas the three-phase contraction (channel 2) was delayed by $250 \mathrm{~ms}$ and ended at $250 \mathrm{~ms}$ before the end of the tetanic contraction. The maximal force of coactivated MUs ranged from $20 \mathrm{mN}$ up to $1000 \mathrm{mN}$ (13 MUs) (Fig. 3).

4. Recordings of the force beginning at a constant phase of stimulation followed by sinusoidal changes in the stimulation frequency were done (rate of changes was $2-4 \mathrm{~Hz}$, three sines; the range of changes of stimulation frequency was $7 \mathrm{~Hz}$ and was matched individually for each MU to evoke unfused tetanic contractions). For a comparison, instead of 


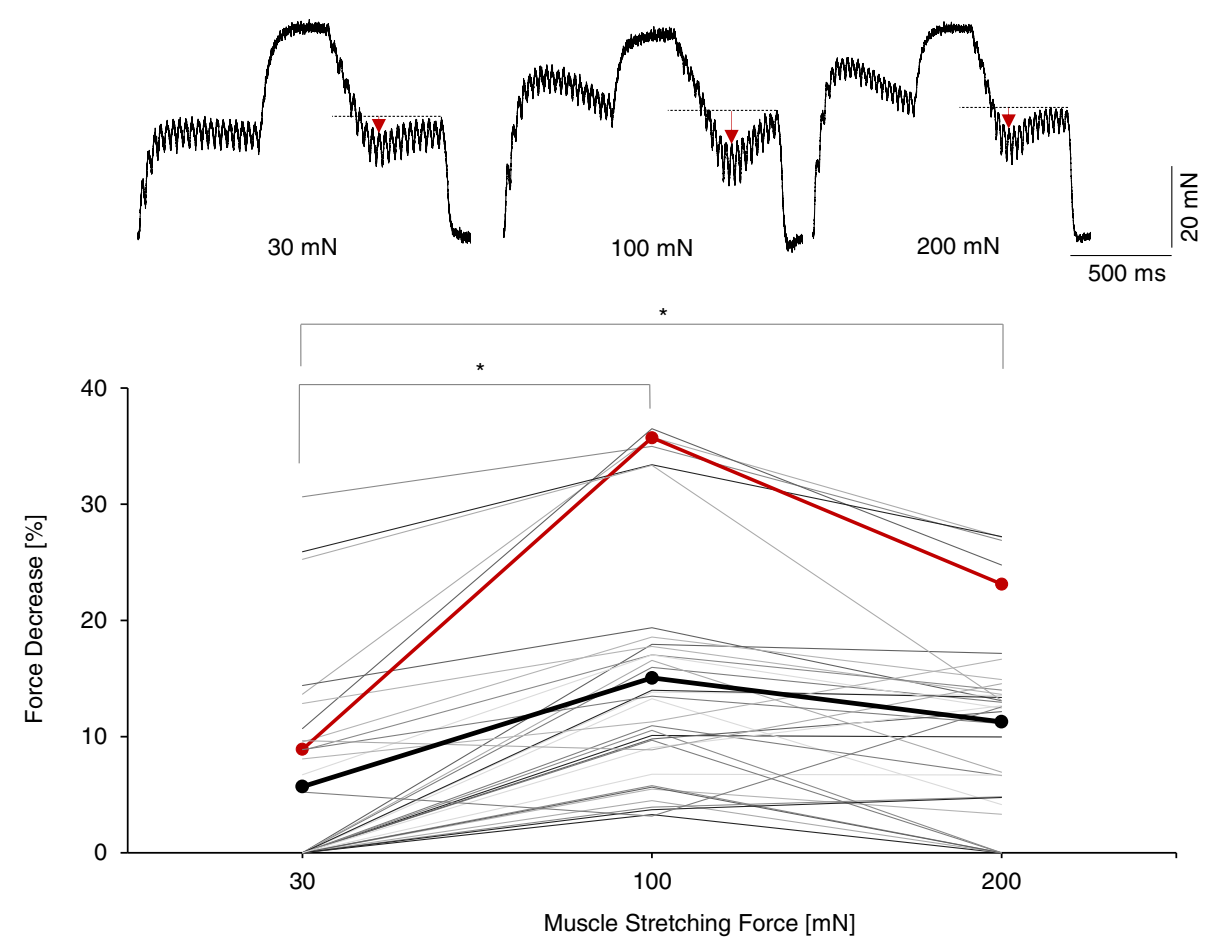

Fig. 1 The influence of the muscle passive stretch on the amplitude of the transitory force decrease. Upper recordings: a set of sample recordings of the tetanic contractions of fast resistant motor unit stimulated with a $30-75-30 \mathrm{~Hz}$ pattern in a muscle stretched up to the passive forces of 30,100, and $200 \mathrm{mN}$. The horizontal interrupted lines indicate the reference force at the end of tetanus used to calculate the amplitude of the force decrease. The red vertical arrows indicate the amplitude of the force decrease. Lower graph: amplitude of the force decrease obtained for the muscle passive stretch values of 30, 100, and $200 \mathrm{mN}$. Data for each set of recordings are connected by a line; the bold red line refers to motor unit illustrated upper. The figure presents combined data for 6 fast resistant motor units for 9 applied stimulation patterns. Note that, at $30 \mathrm{mN}$ for some recordings, the transitory force decrease was not present. The black line connects the mean values at three tested levels of muscle passive stretch; level of significance of differences is indicated above. Significance of differences between groups is represented by $*(p<0.01)$

sinusoidal changes, sudden switches between high and low stimulation frequencies were also applied (9 MUs) (Fig. 4).

5. For $10 \mathrm{MUs}$, the decomposition of their unfused tetanus with the transitory force decrease (recordings within step 4 of the stimulation protocol) into twitch-shape responses to individual stimuli was completed according to a method described previously [23]. Changes in twitch parameters for successive decomposed responses were analysed (Fig. 5).

At the end of recordings for each MU, the fatigue test was performed (trains of 14 stimuli at $40 \mathrm{~Hz}$ repeated each second for $3 \mathrm{~min}$ ) [4].

\section{The analysed parameters}

For the single twitches, the peak force, contraction time (from the beginning of a twitch up to the peak), and half-relaxation time (from the peak up to a moment when the force decreased to $50 \%$ of peak value) were obtained. The studied units were accepted as $\mathrm{F}$ basing on sag in $40-\mathrm{Hz}$ unfused tetanus. The fatigue index (the force generated by $\mathrm{MU}$ after $2 \mathrm{~min}$ of the fatigue test to the initial force) was calculated; for all selected MUs, the index exceeded 0.5. All data are presented as mean $\pm \mathrm{SD}$.

\section{Results}

The influence of passive muscle stretch on the amplitude of transitory force decrease

Among the three applied values of the muscle stretch $(30,100$, and $200 \mathrm{mN})$, the highest effect of the transitory force decrease was observed at $100 \mathrm{mN}(15.1 \pm$ $10.5 \%$ ), whereas, for $200 \mathrm{mN}$ and $30 \mathrm{mN}$, lower amplitudes of the force decrease were noted $(11.3 \pm 8.2 \%$ and $5.7 \pm 9.3 \%$, respectively) (Fig. 1). Although for all selected patterns the transitory force decrease was visible at 100 $\mathrm{mN}$, at $30 \mathrm{mN}$ for 21 and at $200 \mathrm{mN}$ for 6 out of 35 used patterns, respectively, it was abolished. The 

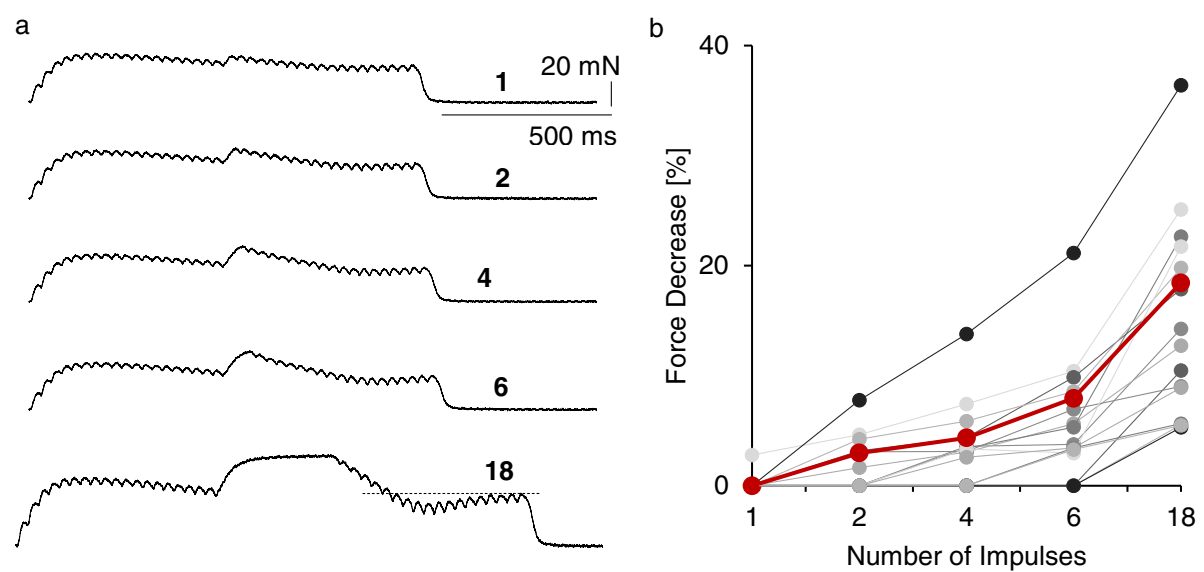

Fig. 2 Development of the transitory force decrease at an increasing number of pulses with high-frequency stimulation. a, a set of sample recordings of single fast resistant contractions evoked by five trains of pulses including one, two, four, six, and 18 short interpulse intervals of $11.1 \mathrm{~ms}$. Low frequency stimulation: $35 \mathrm{~Hz}$; high frequency stimulation: $90 \mathrm{~Hz}$. $\mathbf{b}$, amplitude of the transitory force decrease as a function of the number of short intervals. All data for one set of recordings (obtained at low-frequency stimulations of $35 \mathrm{~Hz}$ and $40 \mathrm{~Hz}$ for all 8 examined MUs) are connected. The black line illustrates motor unit presented left. The red line presents mean values; $p<0.01$ in relation to one short interpulse interval

significance of differences between the compared groups $(30 \mathrm{mN}, 100 \mathrm{mN}, 200 \mathrm{mN})$ was tested using a one-way ANOVA, post-hoc Fisher test.

\section{Dependence of the transitory force decrease on the number of pulses at high frequency}

The effects of shortening of $1,2,4,6$, and 18 interpulse intervals tested for eight FR MUs at 35 and $40 \mathrm{~Hz}$ revealed that the studied force decrease was dependent on a number of high-frequency stimuli (Fig. 2). For all recordings, a shortening of only one interpulse interval did not evoke the transitory force decrease, but, with an increasing number of high-frequency stimuli, said force reduction progressively developed. The significance of differences between the compared groups $(1,2,4,6,18$ impulses) was tested using a one-way ANOVA, post-hoc Fisher test.

\section{The influence of the coactivity of other MUs on the transitory force decrease}

The influence of a parallel maximum tetanic contraction of individual MUs or groups of units generating a large spectrum of forces $(20.4-987.4 \mathrm{mN})$ on the transitory force decrease in selected MUs appeared to be dependent on this force level (Fig. 3). The separate recording with the transitory force decrease was compared to that obtained by removing the force of accompanying tetanic contraction from the common force recording (Fig. 3a vs. 3b and 3d vs. 3e), and the activity of this MU was compared to the force recorded without accompanying activity; subsequently, the differences in amplitude of the transitory force decrease in these two recordings were calculated. For each of $13 \mathrm{MUs}$, several combinations with accompanying groups of units were recorded (yielding a total of 53 sets of recordings). The amplitude of the transitory force decrease was considerably reduced or abolished when the force of coactive MU(s) exceeded $550 \mathrm{mN}$ (Fig. 3g, arrows directed down). At lower forces, the studied phenomenon in some cases even increased (Fig. 3g, arrows directed up).

\section{The transitory force decrease during sinusoidal changes} in the stimulation frequency

When the presence of a transitory force decrease was tested at progressive, sinusoidal changes in the frequency of stimulation, the force decreased to the lowest level at a low stimulation frequency within the first cycle (the mean difference in comparison to the following cycles amounted to $23.9 \%$ ) (Fig. 4b). In separately recorded tetanic contractions, when the stimulation suddenly switched several times between high and low frequencies instead of presenting sinusoidal changes, the transitory force decrease was also visible at the first reduction of the frequency (Fig. 4a).

\section{Decomposition of the tetanic contraction with the transitory force decrease into responses to successive stimuli}

To explain changes in responses to individual stimuli leading to the transitory force decrease, the decomposition of selected contractions into a series of twitchshape responses was performed. The contraction for decomposition was obtained as a difference between the three-phase (low-high-low) and the two-phase (low- 


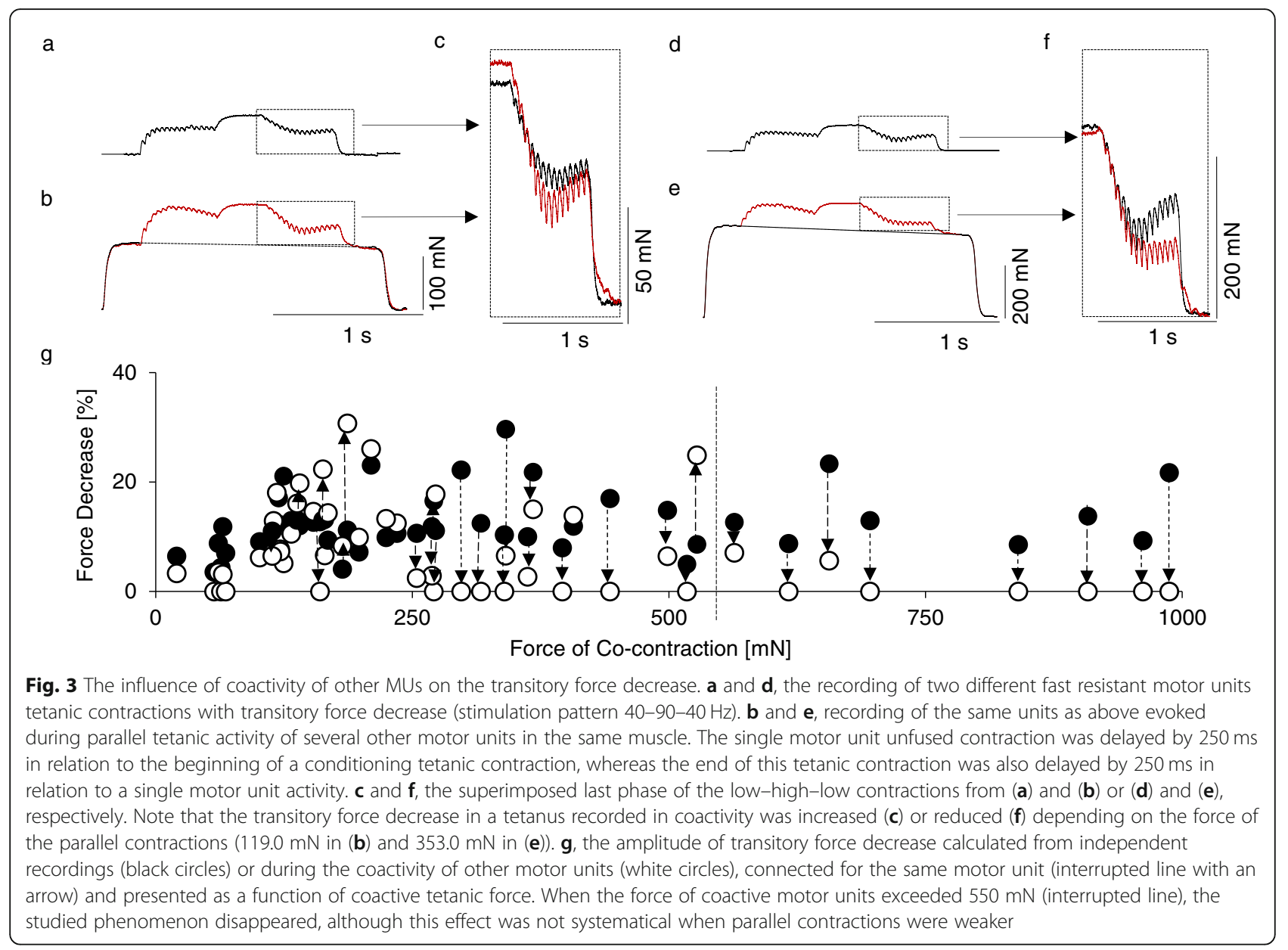

high) recordings (Fig. 5a-c. The amplitude of the transitory force decrease ranged between 5.3 and $36.4 \%$. The analysis revealed that the force decrease resulted from a decrease of amplitudes of the decomposed twitches and a shortening in the contraction time, whereas the following force increase was an effect of a prolongation in relaxation (Fig. 5d-h).

\section{Discussion}

The presented results indicate that a recently reported transitory force decrease [16] is not related to a decrease in the force generated by muscle fibres but rather to a deterioration in the transmission of the force to the tendon. The structures involved in this process are likely intramuscular collagen, althought it is possible that other muscle proteins as titin, the muscle fiber elastic structural protein [18] or even muscle fibres surrounding active MUs might be taken into consideration.

The transitory force decrease following a sudden reduction in stimulation frequency appeared to be dependent on several biomechanical conditions, specifically muscle passive tension (Fig. 1) and coactivation of other MUs in this muscle (Fig. 3). It is known that MU force is dependent on muscle stretches [24] as well as may be modified by the coactivity of other MUs [13]. The MUs of rat medial gastrocnemius generate the highest twitch force at a muscle passive tension of $100 \mathrm{mN}$ [6], whereas the twitch duration expands with an increase of muscle passive tension. The transitory force decrease was evidently the strongest at $100 \mathrm{mN}$, which is optimal for the twitch force (Fig. 1). This observation may be related to stretch-modified properties of the collagen surrounding the contracting $\mathrm{MU}(\mathrm{s})$ or neighbouring, nonactive muscle fibres. Contracting muscle fibres pull the surrounding intramuscular collagen against the external load. Meijer [19] reported that a common system of the myofibril connections of two neighbouring muscle fibres to the same collagen in the basal lamina had an impact in force generation. The decrease in stimulation frequency evokes a sudden reduction in contractile force. The force reduction develops faster than an adaptation of passive parts of a muscle to reduced transmitted force, leading to the transitory force decrease. At a high $(200 \mathrm{mN})$ or low $(30 \mathrm{mN})$ applied muscle 


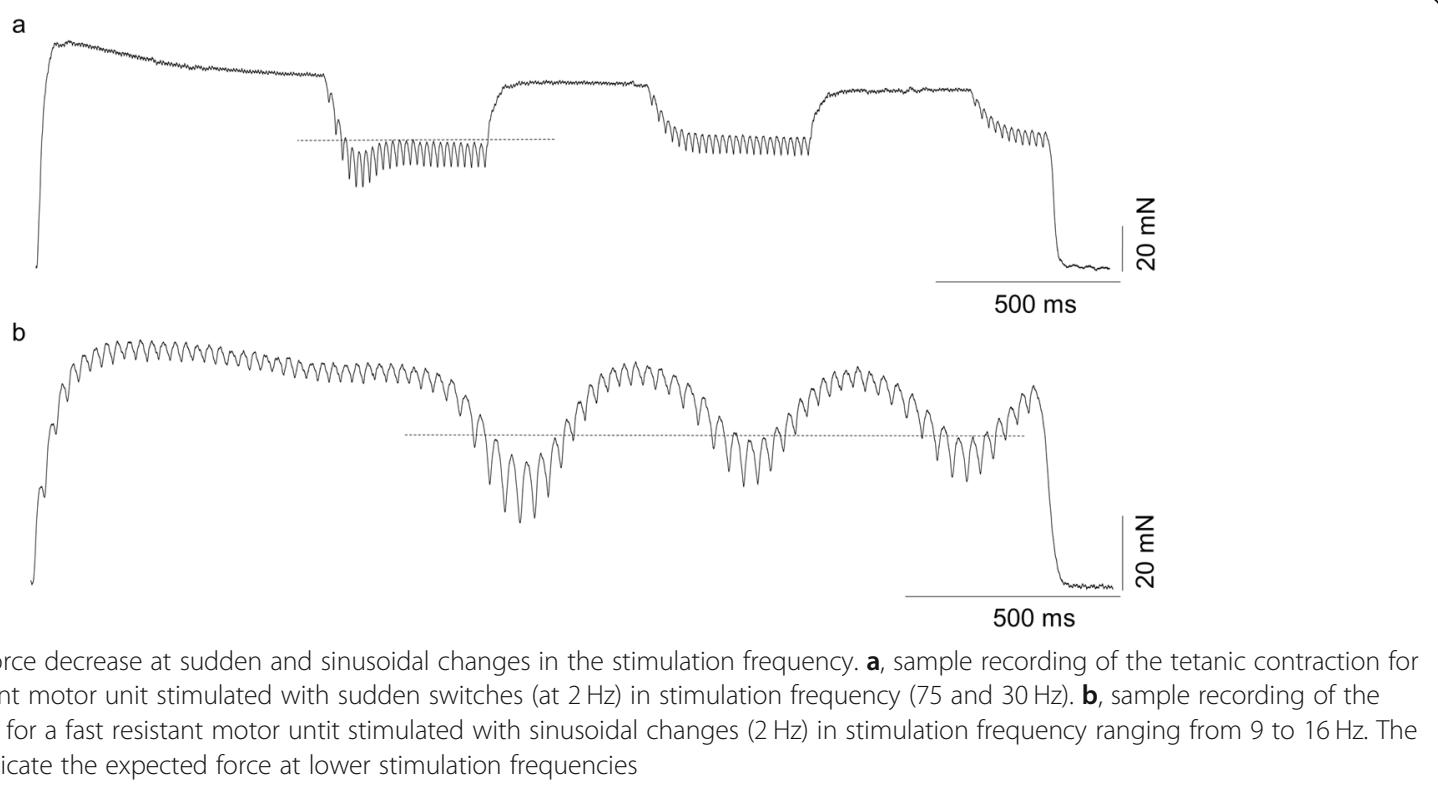

stretch, the passive structural proteins of muscle fibres have modified elastic properties, leading to a decrease in the amplitude of the studied phenomenon when compared to the optimal muscle stretch $(100 \mathrm{mN})$ when the twitch force in isometric recording is the highest [6].

The transitory force decrease may be reduced by coactivation of other MUs. This observation explains why this phenomenon was not observed in similar experiments (also based on low-high-low frequency of stimulation) on human muscles stimulated via the nerve [14]. The present results show that, when the force of coactive MUs exceeded $550 \mathrm{mN}$, the transitory force decrease disappeared. In the studied muscle, the mean value of MU tetanus force amounted to $144 \mathrm{mN}$, whereas the force of the muscle stimulated via nerve was $5.25 \mathrm{~N}$; the muscle consists of 52 MUs [11]. Therefore, the contraction of approximately 10 to $15 \%$ of the MUs (4-5 MUs in a studied muscle) is sufficient to abolish the studied phenomenon. It is possible that territories of two to three MUs do not overlap substantially. With increasing number of coactive MUs and overlapping of their territories, the likelihood that their muscle fibres are neighbours and transmit force by the same parts of collagen is also increased.

The MU force is sensitive to a pattern of activating stimuli; even a change in the first interpulse interval modifies the force production (see Background). Therefore, we tested whether the shortening of one interpulse interval is a sufficient enough action to evoke a transitory force decrease (Fig. 2). However, this phenomenon appeared after a longer series of pulses at a high frequency. This observation contrasts previously described effects of an initial doublet of stimuli or prolonged initial interpulse interval. The catch effect as well as tetanic depression probably depends on intracellular changes of the calcium level [ 1 , 2 , 17]. The transitory force decrease needs longer trains of high-frequency stimuli, which supports disturbances in the force transmission as a possible mechanism. This suggestion is supported by the observation that transitory force decrease occurs most frequently in FR MUs, distributed in the proximal compartment of the medial gastrocnemius [12] and covering only $40 \%$ of the muscle length [26], indicating that force must be transmitted to the tendon by long intramuscular collagen structures.

The decomposition of tetanic contractions revealed that the transitory force decrease is related predominantly to a shortening of the contraction time and a decrease in the force of decomposed twitches, followed by an increase of the half-relaxation time responsible for the final force recovery. It is worth emphasising that changes in relaxation efficiently influence the production of force during MU activity [25].

Sudden decreases or increases in the motoneuronal firing rate are not observed in voluntary activity. However, the sinusoidal changes in stimulation frequency resemble modulations in motoneuronal firing described in prior papers $[20,22]$. The present results revealed that, at sinusoidal changes in stimulation frequency, the transitory force decrease influences the MU force. Therefore, the described phenomenon potentially influences the force at decreasing firings of motoneurons in vivo, in humans, leading to a force 


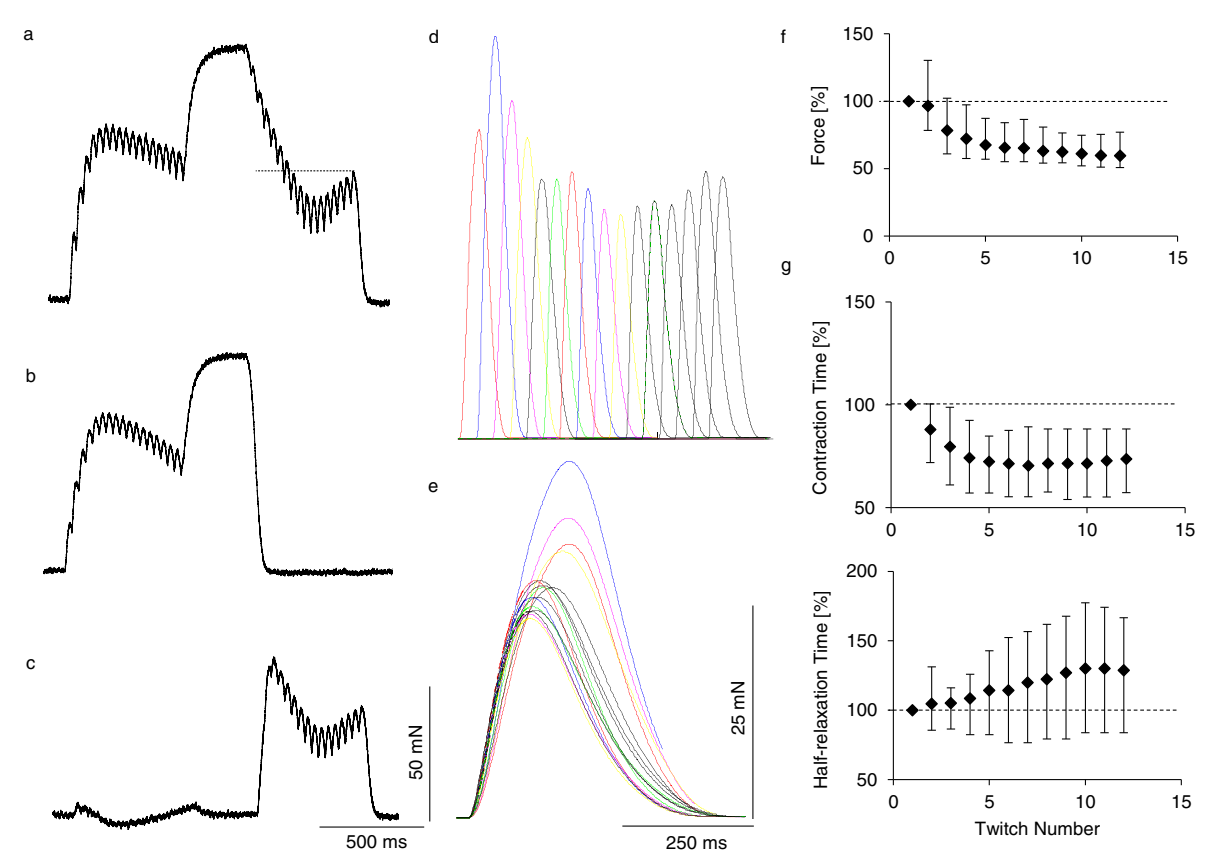

Fig. 5 Decomposition of the tetanic contraction with the force decrease into twitch-shape responses to successive stimuli. a, a single fast resistant motor unit force recording with a low-high-low stimulation frequency pattern. $\mathbf{b}$, recording of the same motor unit at a low-high frequency stimulation. $\mathbf{c}$, mathematical difference between (a) and (b), taken for the decomposition. $\mathbf{d}$, a train of twitch-shape responses to successive stimuli resulting from the mathematical decomposition of recording (c). e, all decomposed twitches presented superimposed with the stimulus time accepted as 0 for all twitches. The contractile parameters of successive twitches for 10 studied motor units (mean \pm SD) presented in relation to the first decomposed twitch (100\%): $\mathbf{f}$ - twitch force, $\mathbf{g}$ - contraction time and (h) - half-relaxation time (mean values and standard deviations). Due to some differences between individual motor units regarding the number of stimuli at the last low-frequency phase (minimum 12), the data are presented for 12 twitches

reduction occurring faster than expected, assuming a linear transmission of firing rate into the force.

\section{Conclusions}

The transitory force decrease is a biomechanical effect most probably resulting from disturbances in force transmission from muscle fibres to tendons by adjacent collagen structures or possibly also other elastic muscle proteins. The phenomenon occurs not only during a sudden switch from high- to low-stimulation frequencies but also at progressive decreases in stimulation frequency, and therefore potentially influences the muscle force at decreasing firing rates of motoneurons during voluntary activity.

\section{Abbreviations}

F: Fast; FF: Fast fatigable; FR: Fast resistant; MU(s): Motor unit(s); S: Slow

\section{Acknowledgements}

Not applicable.

\section{Authors' contributions}

All authors have read and have approved the content of the manuscript. Conceptualization: JC, JR. Data Curation: JR, KK, HDC, RR, JC. Formal Analysis: JC, JR, KK, RR. Funding Acquisition: JR (Grzesiak) - National Science Center (grant No. 2015/19/N/NZ7/01617). Investigation: JR, KK, HDC, JC. Methodology: JC, JR, HDC. Project Administration: JC, JR. Resources: JC, JR, KK. Validation: JC, JR.
Visualization JR, JC. Writing - Original Draft Preparation: JC, JR. Writing - Review \& Editing: JR, KK, HDC, JC.

\section{Funding}

The study was supported by the Polish National Science Center (grant no. 2015/19/N/NZ7/01617). NCN is a government agency, supervised by the Ministry of Science and Higher Education, set up in 2011 to support basic research in Poland.

\section{Availability of data and materials}

The datasets used and/or analysed during the current study are available from the corresponding author on reasonable request.

\section{Ethics approval and consent to participate}

All procedures were made to minimize the suffering of the examined animals and were approved by the Local Ethics Committee for Experiments on Animals (number of Permission: 2/2015). Additionally, various principles of laboratory animal care (Guiding Principles for the Care and Use of Animals in the Field of Physiological Sciences, the Polish Law on the Protection of Animals, and European Union regulations) were followed.

\section{Consent for publication}

Not applicable.

\section{Competing interests}

The authors declare that they have no competing interests.

\section{Author details}

'Department of Neurobiology, Poznan University of Physical Education, 27/ 39 Królowej Jadwigi Street, 61-871 Poznań, Poland. Institute of Biophysics and Biomedical Engineering, Bulgarian Academy of Sciences, Sofia, Bulgaria. 
Received: 19 March 2020 Accepted: 3 September 2020

Published online: 29 September 2020

\section{References}

1. Allen DG, Lamb DG, Westerbald $H$. Skeletal muscle fatigue: cellular mechanisms. Physiol Rev. 2008;88(1):287-332.

2. Allen DG, Westerblad $\mathrm{H}$. Role of phosphate and calcium stores in muscle fatigue. J Physiol. 2001;536(3):657-65.

3. Boe SG, Stashuk DW, Brown WF, Doherty TJ. Decomposition-based quantitative electromyography: effect of force on MU potentials and MU number estimates. Muscle Nerve. 2005:31(3):365-73.

4. Burke RE, Levine DN, Tsairis P, Zajac FR. Physiological types and histochemical profiles in MUs of the cat gastrocnemius. J Physiol. 1973; 234(3):723-48

5. Burke RE, Rudomin P, Zajac FE. The effect of activation history on tension production by individual muscle units. Brain Res. 1976;109(3):515-29.

6. Celichowski J, Grottel K. The dependence of the twitch course of medial gastrocnemius muscle of the rat and its MUs on stretching of the muscle. Arch Ital Biol. 1992;130(4):315-25.

7. Celichowski J, Krutki P, Łochyński D, Grottel K, Mrówczyński W. Tetanic depression in fast MUs of the cat gastrocnemius. J Physiol Pharmacol. 2004; 55(2):291-303.

8. Celichowski J, Raikowa R, Adajov H, Krutki P. Dynamic changes of twitchlike responses to successive stimuli studied by decomposition of $\mathrm{MU}$ contractions in rat medial gastrocnemius. J Neurophysiol. 2014;112(12): 3116-24.

9. Celichowski J. Tetanic depression: a phenomenon influencing the production of tension in fast twitch MUs in rat medial gastrocnemius. Acta Neurobiol Exp. 2001;61:119-23

10. Celichowski J, Grottel K, Bichler E. The area under the record of contractile tension: estimation of work performed by a contracting MU. Acta Neurobiol Exp. 1998:58:165-8.

11. Celichowski J, Drzymała-Celichowska H. The number of MUs in the medial gastrocnemius muscle of male and female rats. J Physiol Pharmacol. 2007. 58(4):821-8.

12. De Ruiter CJ, De Haan A, Sargeant AJ. Fast-twitch muscle unit properties in different rat medial gastrocnemius muscle compartments. J Neurophysiol. 1996;75(6):2243-54.

13. Drzymała-Celichowska H, Celichowski J. Summation of MU forces in rat medial gastrocnemius muscle. J Electromyogr Kinesiol. 2010;20:599-607.

14. Frigon A, Thompson CK, Johnson MD, Manuel M, Hornby G, Heckman CJ. Extra forces evoked during electrical stimulation of the muscle or its nerve are generated and modulated by a length-dependent intrinsic property of muscle in human and cats. J Neurosci. 2011;31(15):5579-88

15. Gorassini M, Eken T, Bennet DJ, Kiehn O, Hultborn H. Activity of hindlimb MUs during locomotion in the conscious rat. J Neurophysiol. 2000;83(4): 2002-11.

16. Grzesiak J, Kryściak K, Drzymała-Celichowska H, Celichowski J. Transitory force decrease following a sudden reduction in stimulation frequency in MUs of rat medial gastrocnemius. J Electromyogr Kinesiol. 2019;46:14-20.

17. Łochyński D. Celichowski J. Tetanic depression and catch-like effect in fast motor units of the rat medial gastrocnemius at linearly increasing and decreasing stimulation frequencies. J Muscle Res Cell Motil. 2009;30(3-4): 153-60.

18. Herzog JA, Leonard TR, Jinha A, Herzog W. Are titin properties reflected in single myofibrils? J Biomech. 2012:45(11):1893-99.

19. Meijer HJM. Aspects of epimuscular myofascial force transmission: a physiological, pathological and comparative-zoological approach. Amsterdam; 2007. thesis

20. Moritz CT, Barry BK, Pascoe MA, Enoka RM. Discharge rate variability influences the variation in force fluctuations across the working range of a hand muscle. J Neurophysiol. 2005;93(5):2449-59.

21. Nakamura H, Yoshida M, Kotani M, Akazawa K, Moritani T. The application of independent component analysis to the multi-channel surface electromyographic signals for separation of MU action potential trains: part I-measuring techniques. J Electromyogr Kinesiol. 2004;14(4):423-32.

22. Person RS, Kudina LP. Discharge frequency and discharge pattern of human MUs during voluntary contraction of muscle. Electroencephalogr Clin Neurophysiol. 1972;32(2):471-83.
23. Raikova R, Celichowski J, Pogrzebna M, Aladjov H, Krutki P. Modeling of summation of individual twitches into unfused tetanus for various types of rat MUs. J Electromyogr Kinesiol. 2007;17(2):121-30.

24. Rassier DE, Maclntosh BR, Herzog W. Length dependence of active force production in skeletal muscle. J Appl Physiol. 1999;86(5):1445-57.

25. Smith IC, Ali J, Power GA, Herzog W. The sag response in human muscle contraction. Eur. J Appl Physiol. 2018;118(5):1063-77.

26. Taborowska M, Bukowska D, Drzymała-Celichowska H, MierzejewskaKrzyżowska B, Celichowski J. Morphometric properties and innervation of muscle compartments in rat medial gastrocnemius. Somatosens Mot Res. 2016:33(3-4):200-8.

27. Vanden Noven S, Gardiner PF, Seburn KL. Motoneurons innervating two regions of rat medial gastrocnemius muscle with differing contractile and histochemical properties. Acta Anat. 1994;150:282-93.

\section{Publisher's Note}

Springer Nature remains neutral with regard to jurisdictional claims in published maps and institutional affiliations.
Ready to submit your research? Choose BMC and benefit from:

- fast, convenient online submission

- thorough peer review by experienced researchers in your field

- rapid publication on acceptance

- support for research data, including large and complex data types

- gold Open Access which fosters wider collaboration and increased citations

- maximum visibility for your research: over $100 \mathrm{M}$ website views per year

At BMC, research is always in progress.

Learn more biomedcentral.com/submissions 